my: colleagues and men of science in these British Isles, that you retain for yourselves and hand down to your successors at least without further impairment the means of promoting medical knowledge and thus of benefiting mankind.

\section{RATS AND PLAGUE}

\section{BY G. J. BLACKMORE, M.B., C.M. EDIN.}

FORMERLY CHIEF PLAGLE 'MFDICAL OFFICER, PORI ELIZABETH ; AND PLAGUE MFDICAT OFYICER, BOMISAY AND CALCUTTA.

THE following notes on the outbreak of plague in Port Elizabeth in 1901 are contributed for the purpose of showing the part played by rats in the dissemination of the disease. The cases given in detail are those that occurred from the beginning of the outbreak on April 16th to July 30th.

On April 12th six dead rats were found in a stack of mealies (maize) on Harbour Board property at the foot of $J$ etty-street. These mealies came from the River Plate and were discharged from the vessel in March. A secund stack of mealies adjoining the one already mentioned was subsequently found to contain some dead rats There mealies also came from the River Plate, but by another vessel, and were discharged in February. The viere of ground on which the mealies were placed is close to the jetty and is surrounded by Harbour Buard sheds and stores. The mealies as well as a quantity of oats and forage stacked on this area belonged to the military authorities. One of the rats found on April 12th was examined by Dr. A. Edington, the Government bacteriologist at Grahamstown, who found considerable numbers of plague bacilli in the organs, and a guinea-pig inoculated from this rat died from plague.

CAsk 1.-April 16th. The patient was a Kafir labourer who had been working on the stacks of mealies standing on the area mentioned. He lived in a large native location outside the town and probably two miles in a direct line from where he worked. No other case of plague had occurred in this location up to the time of my leaving Port Elizabeth on August 21st.

CASE 2.-May 6th. The patient was a Kafir labourer. Between April 12th and May 6th numerous dead rats were found in the area on which the stacks were standing and rome were found in all the stores bounding this area. 'This second patient had been working in these stores. Some of the rats found dead were subjected to bacteriological examination and were found to be infected with plague. This man lived in a second locaticn, about half a mile from the ine where the patient in Case 1 was found, but the length of time that elapsed between the two cases shows that the second patient was not infected from the first. No second case of plague occurred subsequently in this location.

CASE 3. - May 20th. The patient was a European staff sergeant who worked in "I" store, one of the Harbour Board stores already mentioned as formine the boundary to the infected piece of ground. He was taken ill on May 17th and it was then discovered that for some little time pre viously he had been sleeping and taking his food in this shed contrary to orders. Dead rats were found in the shed some days prior to the date on which this case occurred; none of these were examined, but about this time rats were reported to be dying in the searcher's office at the Custom House, a building situated within a few feet of one of the mealie stacks near the jetty and only a few yards from the above. mentioned store, and on May 17 th a rat was seen to come out of its hole in the searcher's office and to die on the floor This rat was examined and was found to contain plague bacilli.

From the date of finding the first case of plague the wilitary and Harbour Board authorities instituted a vigorous crusade against rats. Disinfectants were also freely used about all the sheds, the floors being regularly scrubbed with disinfectants. Fences were erected around the stacks of grain and forage with a view to confining the infected rats within them and as the grain and forage were removed all rats found were killed and the ground was covered with lime. The rat-catcher appointed by the military authorities succeeded in catching a large number of rats. After about the end of May very $f \in w$ rats were to be found either among the grain or in the shed and the three cases of plague already mentioned were the -only ones treed to this primarily infucted area. Up to this time dead rats had not been reported from anywhere in the town excepting the area from which the patients in Cases 1,2 , and 3 came and it was hoped that by fencing in the stacks after infected rats had been fout $d$ amongst them the infection might be limited to this area. but the attempt so to limit the infection failed.

CASE 4. - May 19th. This patient was a Cape coloured female, living in a good quarter of a town a considerable distance from the infected area the source of infection in this case was never traced.

CASE 5. - May 25th The patient, a native storekeeper, was taken ill on May 24th. He lived in a portion of the town known an the Strangers hocation. It is situated probably a mile frum the intected area already referred to and, unlike the other native locations, is within the town. Some of the "contacts" in this case reported that dead rats had been lound in the shop and yard a short time previously. When the floors of the house were taken up three dead rats were found, one being underneath the floor of the room in which the patient slept. Unfortunately, these were destrosed im. mediately by the inspectors. The patient stated that he obtained most of his goods from one of the large stores in the main street of the town, and in this store a case of plague occurred on June 13th.

Case 6. - May 30th. This case occurred in a Kafir boy who worked in a barber's shop in Jetty-street. This shop is situated about 60 or 70 yards from the store in which Ca:e 3 occurred and is in the same street as the front of the Custom House referred to under Case 3 anci about 40 yards from it. The harber's shop was on the ground floor of a large store and in this store dead rats were found some days before the boy was taken ill. One of the: e rats, examined on May 27th, contained plague bacilli. The shop in which the fratient worked is situated north-west of the original area of infection, and it seemed from the reports about dead rats received at this time that the infected rats were making their way northwards through the town and this idea was confirmed by subsequent events.

CASE 7.-June 3rd. The patient in this case was a male Fingo living in Strangers' Location and working in a :tore within a few yards of the place $x$ here Case 6 occurred.

CASE 8. - June 10th. The patient was a male Kafir working in a private store clo:e to the original area of infection. This man lived in Reservoir Location which is situated some distance outside the town and nearly three miles from the jetty.

Although no dead lats were reported from the stores in which the patients in Cases 7 and 8 worked there were infected rats in adjoining stores, as shown under Case 6.

CASE 9.-June 14th. The patient was a male Kafir working on one of the lighters employed in carrying cargo between ships in the bay and the shose and was seen on June 14th. He lived at the extreme north end of the tuwn in a place known as Vlei Post. No previous case of plague had been reported within two miles of this place. On June 8th about 30 dead rats were found in a small table in a timberyard situated not far from the place where this patient is said to have lived. An examination of one of these rats disclosed numbers of plague bacilli. The forage was then turned out of the stables and the bodies of 170 rats and mice were found. Most of the rats had been dead for some time. How infected rats reached this part of the town still remains a mystery. Shortly after these rats were found a boy who had been working in the stables was reported to be away from work ill and he is said to have died a day or two later in a village outside the town, but his body was never found and is supposed to have been buried on the veldt by relatives.

CASE 10.--June 15th. The patient was a European male working as a packer in a large private store in the main street of the town. This store is within a few yards of the place where Case 6 occurred. The patient was taken ill on June 13th. Seven or eight days before this a case of caps in the store was found to contain rats' nests. The caps were badly gnawed by the rats, and a dead rat found on June 8th in this case was sent for examination and was ascertained to contain plague bacilli. The patient and a native boy were sent to turn out these caps and to sort out the damaged ones with a view to their being destroyed. The European contracted plague and developed a femoral bubo ; the native did not contract plague. It was from this store that the patient in Case 5 obtained most of his goods, and it seems probable that by means of these goods, or more probably bv the carriage of an infected rat amongst them, plague was introduced among the rats in Strangers' Location. 
CASE 11.-June 19th The patient was a male Kafir working as a storeman in one of the largest stores in the town situated not far from the stores roentioned in Cases 6, 7, and 10, and living in Strangers' Location. He was taken ill on June 16th. No rats were found in his house and none were reported from the store in which he worked, but undoubtedly there were infected rats in the immediate vicinity of this store, as already shown, and there were probably also infected rats in the vicinity of the house

CAsE 12. - June 20th. The patient was a Cape coloured boy employed as a stable-boy in Sea-lane. This lane is situated about a quarter of a mile north of the store mentioned in Case 10. On June 17th a dead rat was found in the stable and it contained plague bacilli. The boy slept in a small room off the coachhouse attached to the stable. The coachhou=es and room were thoroughly disinfected and cleansed. Two other stable-boys who worked with the patient were inoculated on June 22nd with Yersin's serum. One of these contracted plague on July 4th, as detailed below.

CASE 13.-June 22nd. The subject of this case was a Kafir girl, aged 14 years, whose body was taken to one of the plague officers. The place of residence was never ascertained but the mother of the girl worked as a washerwo van in the south end of the town and the girl assisted her. In the vicinity of some of the places where the mother and child are said to have worked dead rats were found in the street (see Cases 25 and 29).

Case 14 - June 23rd. The patient was a Polish Jew who was out of work and who lived in a second-rate store at the north end of the town. Most of the clothes in the store were bought at sales in Queen-street which lies within a rat-infected area. No previous case of plague had occurred in the immediate vicinity of the patient's dwelling.

CASE 15. - June 23rd. The patient was a European male, aged 19 years, working as a storeman only a short distance from the place in which Case 6 occurred. He was taken ill on June 20th. He stated that previously to his illness dead rats had been found in the store where he worked. None of the-e, however, were submitted for examination.

CASE 16.-June 27th. The patient, a coloured boy working in a stable at the south end of the town was taken ill on June 24th. On May 22nd several dead rats had been found in a store within a few yards of this stable. One of them was examined and was found to contain plague bacilli. This store contained second-hand goods and the proprietor of the stable had complained on several occasions of the condition of the store and the number of rats to be seen about it.

CASE 17.- June 27th. This was the case of a European boy working as an office boy in Main-street. The stores at which this boy worked were infested with rats and dead rats were found on the plemises the day after he was taken ill. One of these was submitted to examination and was found not to contain plague bacilli. There were, however, undoubtedly infected rats in the vicinity and probably in the stores, as the store from which the patient in Case 10 was removed was within a few yards of the place.

CASE 18.-July 2nd. The patient was a Kafir working in a store within 30 yards of the store in which the patient in Case 3 had lived. No dead rats had been reported from this store

CASE 19.-July 4th. The patient was a European female living in the north end of the town and working in a shop in Main-street about 50 yards from the stables mentioned in Cases 12 and 22. Two dead rats were found in the store below the shop. These were not examined.

CASE 20.-July 5th. The patient, a Hindoo syce working and living in the military remount camp in the Show Yard at the north end of the town, was taken ill on July 3rd and was removed to hospital on the 5th. This syce slept on some forage in one of the stables, and on turning out this forage about 20 dead rats were found and one of these contained numerous plague bacilli. Most of the forage in this camp had originally been stored at the south end of the town, and it seems probable that infected rats were conveyed with the forage from the south end to the remount camp.

CASE 21. - July 6th. This patient was a Kafir working as a labourer in the market. The market is infested with rats and is not more than 70 or 80 yards from the area first found to be infected, but no dead rats were ever reported from the market. This man lived at the north end of the town, nearly three miles from his place of work and within a short distance of the stable mentioned in Case 9.
OAS 2 22.-July 6th. A Kafir male, working as a stablebry in the same stable as the patient mentioned in Case 12, was taken ill on July 5th and was removed to hospital on the 6th. This was one of the persons incculated with Yersin's serum on June 22nd. He slept in a corner of one of the stables. When the stables and coachhouses were cleared out about 50 dead rats were found. Some of these were in the partitions of the stalls of the stables in which this boy slept. Others were found under the floors of the rooms, in one of which the patient in Case 12 slept. One of the dead rats was examined $n n$ July 7 th and was found to contain large numbers of plague kacilli. It will be remembered that an infected rat was also found in this place on June 17th.

CASE 23. - July 7th. The patient was a Kafir male working as a stable-boy and sleeping in the remount camp in the Show Yard. He was said to have been taken ill on July 3rd, the date on which the patient in Case 20 was taken ill. Under Case 20 will be found particulars of the dead rats found in this place on July 5 th. As a result of these two cases of plague the whole of the Show Yard was evacuated and the persons living in it were removed into tents on the veldt outside. No further case of plague occurred amongst the perions so removed until July 30 th, and the man who was then attacked was removed as a "contact" in this case and worked in the Show Yard assisting in the cleansing operations after he had been released from the contact camp.

CASE 24.-July 8th. In this case the patient was a European female, aged 13 years. The source of infection was not traced.

CASE 25.-July 9th. A coloured female. aged 11 years, living in the south end of the town, was taken ill on July 7th. On several occasions within the previous two or three weeks dead rats had been found in the street within a few yards of the house, but none of them had been examined.

CASE 26 - July 17th. The patient, a Hindoo living in the north end of the town, was taken ill on July 15th. There was evidence of rats in the house in which tice patient lived. The actual source of infection was not traced.

CASE 27.-July 18th. The patient was a Hindoo hawker, living in a street a short distance east of Strangers' Loca. tion. A dead rat was found under the floor of his hut but there was no evidence that it died from plague. A plagueinfected rat was, however, found in the street at the back of the patient's house on July 18th.

CASE 28.-July 19th. The patient was a male Kafir working on one of the lighters in the harbour and living at the north end of the town, about 100 yards from the stable mentioned in Case 9.

CASE 29. - July 20th. In this case the patient was a coloured boy living in the south end of the town. Some dead rats and mice were found under the floors of the house, but they were too decomposed for examination. This patient came from a house about 30 yards from that in which lived the patient in Case 25 . In both cases the patients were children and no other cases had occurred in the neigbbourhood. As mentioned under Case 25, dead rats had been found in the streets in the immediate vicinity.

CASE 30.-July 20th. The patient was a Kafir boy, aged 12 years, living at Strangers" Location. Dead rats were found in the streets in the vicinity of this house on July 10 th and $13 \mathrm{th}$, and in each case examination showed that they were infected.

CASE 31.-July 21st. This patient, a male Fingo working as a labourer in a store in Main-street, lived in the Reservoir Location and worked in an infected area, but no dead rats had been reported from the store in which he worked.

CASE 32.-July 22nd. This patient was a Japanese female. No definite information could be obtained as to the source of infection, but she frequented the street from which Case 27 came.

CAsE 33.-July 30th. This patient, a male Fingo living in the horse kraals in the remount camp a short distance north of the Show Yard, was removed to hospital on July $30 \mathrm{th}$ and had probably been ill for three or four days. He was removed to the contact camp on July 7th in connexion with Case 2.3 and was released on the 19th. After this he worked he said, in cleaning out the stables in the Show Yard. These cleansing operations were undertaken by the military authorities in consequence of cases of plague (Cases 20 and 23 ) having occurred there.

I have detailed all the cases that occurred up to Jaly 30th 
to show that selected cases have not been picked out in order to strengthen the case against the rats. It seems unnecessary to detail more cases and I shall therefore content myself with giving the general results of the observations made on the cases that occurred during the remaining three weeks that 1 stayed in Port Elizabeth.

In connexion with Case 27 it may be noted that two other Hindoos living in the same street as, and close to, the patient mentioned in this case contracted plague, one on August 8th and the other on the 14th. The houses in which these two persons lived were opposite each other and there was frequent communication between the two places. The putrid bodies of six rats were found under the floors in the case of the last patient.

On August 14th a case came from Victoria-street, close to Strangers' Location, and two dead rats were found under the ffloors. A week later three cases, all of Chinamen, came from a small shop in the same terrace of houses and only two doors away. Under the floor some 20 dead rats were found and these were proved to be infected. At the time that these three cases were found another case occurred in a European boy living in a good-class house in the same street. The source of infection was not at the time apparent, but it was shown later that a few days before his illness the boy had been in the Chinese shop mentioned and was therefore there just about the time that the Chinese inmates contracted the disease. The relatives of the boy did not contract plague and no dead rats were found in the house in which he lived.

On August 18th a case occurred in a Kafir working and living in a plantation some distance, probably one and a half miles, south of the town. The workmen lived in three or four huts in the plantation and there were no other houses near the place. About the same time the European foreman working at this place and living in a part of Port Elizabeth from which no cases of plague had come and in which no dead rats had been found died from the disease, and a few days later another native working and living in the same place was taken iil. Dead rats were then found in some forage near the workmen's huts, and some of this forage is said to have come from an infected part of the town.

\section{Analysis of Cases.}

An analysis of the 33 detailed cases brings out further evidence to prove that rats were mainly, if not wholly, responsible for the spread of plague in Port Elizabeth, at any rate curing the first four months of the outbreak. This analysis shows that:-

1. Relatives of pationts did not contract the disease. In only one case did two members of the same family contract 3 in 30 ; and in this case the idea that

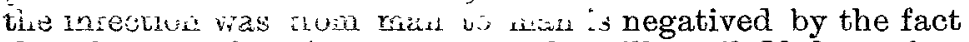
that the second patient was not taken ill until 20 days after contact with the first. But both patients worked at the same place and it has been shown to have contained infected rats.

2. "Contacts" did not contract plague. In only two cases did "contacts" of these 33 plague cases contract plague. One case was that just mentioned and the other was Case ?2, and in this latter case again the second patient

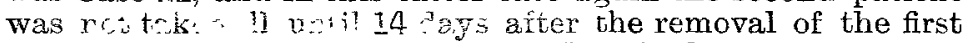
(Cise 12) ara wow pauleries worked and slept in the same rat-infected dwelling.

3. Neighbours of plague patients did not contract the disease. Had the infection been from man to man the house in which a plague patient lived would have shown itself a centre co infection by persons living in adjoining houses and who frequented the patient's house becoming infected, but this never occurred except where dead rats were found in the patient's dwelling-house.

4. The dwelling-houses of the patients were widely separated, but nearly all the patients worked in the same rat. infected area. The 33 cases were widely scattered over the town as regards the dwelling-places of the patients and there was not the slightest evidence in the earlier cases of plague that any patients contracted the disease in their own homes. As alrealiy stated, the "contacts" did not contract the disease and the houses in the vicinity of those in which plague patients lived did not become infected until such time as plague rats appeared in the houses in their immediate neighbourhood. But nearly the whole of the patients-29 out of 33 -worked in the area which was proved by bacteriological examination to contain infected rats. It was only when infected rats made their way to the residential portion of the town that cases of plague began to appear amongst persons who did not work in the business part of the town where infected rats first appeared. Of the first 23 cases only one person did not work in a rat-infected area. This exception was a coloured servant and it was the only case out of the 23 where a patient who worked in the same place as he lived contracted plague, and up to this time only two children had contracted the disease and both of these worked in the infected area. But as the infected rats were traced to the residential part of the town cases began to occur amongst people who did not work in the town and this is shown by the fact that out of the next 21 cases eight were those of children under 13 years of age. In no case did any relatives or " contacts" in these eight cases contract plague, while in all cases dead rats-in some cases proved to be infected-were found either in the houses in which patients lived or in their vicinity. The southern part of the town is separated from the northern by a stream called the Baakens river, and dead rats were found in only two places south of this river, one place being a store and the other in the extreme eastern part of the area. One case (Case 16) occurred within a few yards of the store mentioned, two others occurred in houses situated in streets in which dead rats were found, and one other patient in this area had been working, and probably sleeping, close to where the rats were discovered. The rats in the store were found by examination to be infected. No other cases of plague were found in this part of the town south of the Baakens river. Most of this area is thickly populated by natives and all the conditions are favourable to the spread of plague if it is conveyed by man-to-man infection. Yet the cases were confined to one part of the area and to that part in which alone dead rats had been found.

A general survey, then, of the course pursued by plague in Port Elizabeth up to August 21st shows that the disease began in rats found in maize stacked close to the jetty at which most of the goods from over sea are received, and this maize had come from an infected port. As long as dead rats were found on this area cases of plague were traced to it ; when dead rats ceased to be found no further cases of plague were traced to this part. Infected rats then made their way along a narrow strip of land lying between the main street of the town and the sea and as they passed northwards cases of plague followed in their wake. Again, in this area when dead rats ceased to be found plague cases ceased to occur. Infected rats were then discovered in four differesit jarts of the town-viz., at the extreme north end, at the extreme south end, in the Strangers' Location near the middle of the town, and in the remount camp. At the same time cases of plague began to come from all these places. At the south end only a few dead rats were found and only four cases of plague occurred there, all close to where the rats were found, the rest of that district remaining free. At the remount camp two cases of plague occurred and these were removed and the camp was evacuated; only one further case occurred among the men turned out of this camp and this patient assisted in the excavation operations. The north end of the town and Strangers' Location and its vicinity still contained infected rats when I left and cases of plague were still coming from those parts.

To sum up shortly, in places where infected rats were found plague cases followed and in places where there were no infected rats only four cases of plague occurred, and in these cases the source of infection could not be traced at all. In no case was there direct evidence of man-to-man infection and in most cases the possibility of it was definitely excluded.

\section{The Mode of Communication from Rats to Man.}

From the evidence obtained in various parts of the world the assumption that rats convey the plague to human beings is unavoidable. But it remains to be shown in what manner the disease is communicated from rats to man and why it is that so few human beings are attacked in proportion to the number of rats that die from the disease. While some persons appear to contract the disease from handling dead rats others are apparently able to handle them with impunity. In most cases, however, there is no evidence that persons who have contracted plague have come into actual contact with rats either dead or alive. In only one case in Port Elizabeth was the patient said to have handled a rat and the patient himself denied that he had done so. In their recent book on plague the Thomsons record the fact that children in India played with dead plague rats 
without contracting the disease and other evidence gues to show that the handling of rats dead long enough to have grown cold is not attended with the same danger as handling rats that are still warm. It would appear, therefore, that although certain persons contract plague when they frequent or sleep in places containing infected rats only a small proportion of persons so exposed contract the disease and that it is apparently not necessary for such persons to have come into actual contact with diseased rats; and it appears also to be the case that there is more danger in handling rats recently dead than in handling those that have been dead for some hours. It seems evident, therefore, that the disease is communieated by some intermediary agent which can pass from rats to man without actual contact between the two and which is found in warm dead rats and not in cold ones. There is good reason for believing that this intermediary is the rat flea. It is well known that it leaves the bodies of rats as soon as they become cold and the plague microbe has been found in the bodies of rat fleas. It is stated that this flea will not bite human beings, but the evidence in support of this contention is slight and inconclusive. The fact that in one or two cases it has been found that the rat flea will not attack man is no proof that it never does so, and the evidence which seems to show that it is only occasionally that this particular flea attacks men-and then only certain individuals-accounts perfectly for what has been stated earlier, that in plague due to rat infection only a limited number of persons are attacked in proportion to the number of rats suffering from the disease. It is stated in a recent and authoritative book on the $\operatorname{dog}^{1}$ that the dog flea never attaches itself permanently to man, although it may annoy him with occasionai visits, and it is extremely probable that the same statement holds true with regard to the rat flea.

Although it is possible that most outbreaks of plague are initiated and carried on up to a certain point by means of rats it is not possible to avoid the conclusion that infection from person to person takes place sooner or later, but here again the presence of some intermediary seems to be apparent, and this agent is probably the human flea. It has been shown on many occasions that plague contracted through mere contact with plague patients, excepting in the case of those suffering from pneumonic plague, is of very rare occurrence, if, indeed, it ever occurs. It is also well known that when persons are removed frnm dirty, vermininfected houses in which plague cases are cunstantly occuring cases of plague among such removed persons are rare, even though such persons are accompanied by others already suffering from the disease. "Contacts" removed from the most grossly infected areas and who wait on their plague-stricken relatives in well-kept hospitals-as they often do in India-rarely contract the disease. But if the human flea does become an agent in the spread of the disease it seems likely that it cannot become infected in a considerable number of cases, even when it feeds on plague patients. Observers are all agreed that the plague bacillus is rarely found in the blood of patients excepting immediately before death, and it is therefore improbable that fleas can become infected and be rendered capable of conveying the disease until this stage is reached. The preponderance of femoral and inguinal buboes appears to be a point in favour of the argument that fleas convey the disease. Anyone who has had much slum work to do in any of the English towns must have noticed that however careful one may be not to sit down and not to handle things unnecessarily it is impossible to prevent fleas from getting on to the legs; this is due to the fact that the floors in some of these dirty slum houses are simply swarming with fleas. In all cases where houses are infested with fleas it will be found, I think, that bites occur much more frequently on the legs than on other parts of the body. Now femoral buboes are the commonest in probably all epidemics of plague. Out of the 33 cases which I have detailed 24 had femoral and six inguinal buboes. It is, of course, asserted that this is due to the fact that the microbe gains access through small cuts or abrasions in the lower extremities, but although certain cases probably arise in this way careful search has failed to show that this mode of entrance is common.

The Destrudtion of Rats.

Before making some remarks on the destruction of rats it may be well to emphasise the fact that the finding of dead rats in a town, especially a seaport, which is exposed to the possibility of being infected with plague, is to be looked upon as a most suspicious circumstance. It is sometimes asked whether plague workers are not too apt to put down these cases to plague without sufficient evidence, and whether many of these deaths are not due to normal mortality, but it is significant that the men who work in rat-infected places are often the first to draw attention to the fact that dead rats are being found, showing that the finding of dead rats is not a common occurrence even in places where they are known to exist in large numbers, and inquiry among workers in stores and sheds has confirmed this impression. The fact is that rats dying from normal causes, and in most cases even from poison, die in their holes or in other inaccessible places. Plague is probably the only disease which causes rats to come out and to die in the open. It is well known now that not only do they do so, but that very frequently they do it in daylight and are seen to come out of their holes, stagger along for a short distance, and then fall dead. Bacteriological examination will, of course, always settle the question as to the cause of death, but deaths among rats are of ten not brought to notice until some time after they have occurred and the bodies have become too decomposed for examination.

From what is now known of the close connexion that exists between plague in rats and in man it is evident that in a country threatened with the introduction of plague it is a matter of vital importance in the first place to try to prevent infected rats from getting into the country, and secondly to do all that can be done to exterminate the rats already in the place, especially in the seaports. But a very short practical acquaintance with the subject shows that the task of preventing rats from gaining an entrance into any particular town and of exterminating those already in the town is one beset with difficulties. Every effort should be made to try to prevent infected rats from leaving a port in which there is plague. Before vessels leave such a port an attempt should be made to kill the rats on board by introducing sulphurous acid gas or carbon dioxide into the hold. There are, however, certain parts of vessels, especially passenger steamers, where it is scarcely practicable for gas to be introduced with any effect, and for this and other reasons any attempt made to kill the whole of the rats on board ship is not likely to be more than partially successful.

In seaport towns it seems almost an impsisibility to prevent rats from getting on shore from ships. Even if protectors are placed on cables and chains rats can drop over the side and swim ashore. When vessels lie out in the harbour and discharge by means of lighters, as they do in Port Elizabeth, it is still possible for rats to get ashore. It will be found that in most lighters there are rats. It is a simple matter for them to get into lighters from ships and thus to get ashore or to infect the rats on the lighters, which in their turn make their way on shore by swimming or otherwise. But probably the commonest way in which rats are conveyed ashore is in cargo. In forage many are carried ashore, and it is stated by the manager of one of the largest milling companies in Port Elizabeth that it is not at all an uncommon occurrence to turn rats out of bags of grain when the bags are opened. In many other articles of cargo it is not only possible but it is quite certain that rats are conveyed ashore. This introduction of infected rats constitutes a far greater danger than that to be apprehended from the occasional introduction of a plague patient into a country. It becomes evident, therefore, that, while what can be done should be done to prevent rats from passing into a vessel calling at a place infected with plague, to kill as many as possible on board ship, and to prevent those left from passing ashore at a non-infected port from such a vessel, the measure on which the greatest reliance is to be placed in keeping a town free from plague is the extermination of the rats in that town, so that if plague is introduced into the place by means of rats the material necessary for its spread will be absent. Some remarks on the chief measures usually adopted for the destruction of rats may therefore be of interest. These measures are the use of traps, poison, dogs and cats, ferrets, poisonous gases, and the introduction of infectious diseases known to be fatal to rats.

Traps. - The use of traps is generally attended with disappointing results, partly because no particular care is usually taken in the use of traps and partly because in a very short time rats appear to get to know the object of the 
traps and to avoid them. Wire traps which will hold severa rats at the same time are probably the best; they should be handled as little as possible and plunged into koiling water immediately after rats have been removed from them in order to keep them free from odour. The baits must be changed frequently; those most acceptable to rats appear to be toasted cheese, oatmeal, sunflower seeds, herrings, or bread, oatmeal, \&c., on which a few drops of oil of aniseed or oil of rhodium have been sprinkled. One bait will often succeed in enticing rats into a trap when others have failed. Cabbage leaves on which oil of aniseed or oil of rhodium has been sprinkled are in great repute in some ports, but the use of these oils proved disappointing in Port Elizabeth. Probably the best results were obtained with sunflower seeds. The large quantity of food within the reach of rats in all towns is responsible to a great extent for the failure which generally attends the use of traps.

Poison. - This, in my opinion, is the measure on which most reliance should be placed for the destruction of rats. Its clisadvantages are obvious: most rat poisons will kill other animals, including children, and many persons object to their use on this account. But if care is used the danger can be reduced to a minimum. By laying the poison late at night, taking it up early in the morning, and shutting up domestic pets during the time that it is laid, there is practically no risk of anything but rats suffering from its employment. Another disadvantage is that rats killed by poison often die under the floors of rooms and the stench arising from their decomposition becomes unbearable. There appears to be no way of avoiding this. Some makers of rat poisons advertise that their poison causes the dead bodies of rats to dry up without emitting any offensive odour, but a poi: on which really does this has not yet come under my notice. The only reply that can be made to the objection that $\mathrm{p}$. isoned rats cause such an objectionable odour is that the odour from dead rats about a place is much less dangerous than the presence of live rats in it when plague is present in the town or likely to be introduced. Most of the advertised rat poisons fulfil the purpose for which they are sold fairly well and some of them give excellent results. A home-made preparation which is highly spoken of is one marte by mixing equal parts of plaster-ot-Paris and oatmeal together. The addition of a drop or two of oil of aniseed protiably makes the mixture more attractive. Trery good results are obtained sometimes by dissolving arsenic in water, but great care must be exercised in its use as the water is vely apt to be drunk by those for whom it is not intended. In certain parts of Port Elizabeth wher: poison was used systematically the reduction in the number of rats was most marked and in some places they appear to have been exterminated. Under thi heading may be mentioned some substances which while not being destructive to rats are yet so objectionable to them as often to cause them to leave the place where they are used; the chief of these are lime, chloride of lime, and carbolic acid. As, however, the driving of infected rats from one place to another is more likely to spread plague than to assist in stopping its spread, the use of these substances in places where there are known to be infected rats would not be advisable were it not for the fact that the three substances mentioned are destructive to fleas; hence the scrubbing of floors with carbulic acid is a measure to be recommended, and as fleas lay and hatch their eggs in sand the laying of lime on the ground around buildings is also a wise precaurion. The lime should be frequently renewed as it soon loses its strength.

Dogs and cats. - No very marked benefits arise from the u:e of these animals when the wholesale destruction of rats is attempted, but they are useful as auxiliaries.

Ferrets. - These animals are employed largely in some places and in the hands of expert rat-catchers good results are obtained, but their use in places where rats are infected with plague is not to be recommended. 20 ferrets were received in Port Elizabeth from England on July 9th. They were worked systematically from about the 20th. On the 30th it was noticed that some of the ferrets were sick. On August 1st two died, and by the 14th 16 out of the 20 had died and the remaining four, then very ill, were killed. Five of the ferrets tr at died were examined. A few organisms resembling plague bacilli were found in the organs of the first, in the second nothing was found, and in the other three plague bacilli were abundant and the postmortem appearances were characteri-tic. As all the ferrets had precisely the same symptoms it is more than likely that all of these contracted plague. The use of ferrets, therefore, in an infected place is not unattended with danger as they may introduce disease among rats not already infected.

Poisonous gases. - The two gases chiefly employed are sulphurous acid gas and earbon dioxide. They may be used in the holds of ships, in stores where the buildings are suitable, and in sections of sewers. In all cases the place into which the gas is introduced should be hermetically closed and the gas should, if possible, be introduced under pressure in order to insure its penetrating into the desired parts. It is scarcely necessary to mention the precautions which must be used in entering places which have been filled with a poisonous gas. In certain cases good results have been recorded from the use of gas, especially in ships' holds and in sewers.

The introduction of infectious diseases amony rats. - The disease on which some hopes have been built is that caused by Danysz's bacillus. That it will cause the death of all the rats amongst which it is introduced is more than doubtful. In order that the disease may spread among rats it is necessary apparently that those that have died or are likely to die from the disease should be eaten by their fellows, and the virulence of the organism rapidly diminishes in these circumstances. Rats shut ap together in a cage will eat each other and they possibly do so to a very limited extent under normal conditions, but if this proclivity is alone relied upon to spread the disease I think that this mode of extermination of rats is destined to result in failure. Oulture of bacillus can, however, be used in the same way as rat poison by soaking pieces of bread in a broth emulsion of a fresh culture and spreading them in places where rats are known to congregate. The adrantage over poisons is that the bacillus is not poisonous to animals other than rats and mice, but on the other hand, the results are not so rapid as in the case of poisons and not apparently so certain. Professor Simpson introduced the bacillus into Port Elizabeth and at his request I fed three rats on cultures and distributed a considerable quantity of bread prepared in the way which $I$ have mentioned in different parts of the town. Of the three rats fed on the virus only one had died at the end of a fortnight and no characteristic bacilli were found in its body. The bread saturated with the cultures was well taken, but no results were apparent up to the time of my leaving Port Elizabeth. Professor Simpson thought that the negative results obtained in this case might be due to the cultures being rather old when used, although Kister and Kottgen consider that the cultures retain their virulence for some weeks. ${ }^{2}$ Fresh cultures were being used when I left and the results will no doubt be made known later.

In concluding this article I desire to express my indebtedness to Dr. Kirton, district plague medical officer, Port Elizabeth, who performed the post-mortem examinations on the bodies of the ferrets and on many of the rats that died in the town and who kindly placed his notes at my disposal ; also to Dr. Edington, Government bacteriologist, and to Dr. Kidd and Dr. Cooper, plague medical officers, Pot Elizabeth, for making several post-mortem examinations of rats and furnishing me with particulars of the same.

High Barnet.

\section{A CASE OF PUERPERAL SEPTICAMIA.}

\section{By A. F. DIMMOCK, M.D. Derh., M R.C.S. ENG.}

THE following case of puerperal septicæmia may be of interest on account of the remarkable variations in the temperature. The patient was a married woman, 20 years of age, and was seen by me on March 10th, 1902, when she was in the fifth month of pregnancy and threatened with a miscarriage. She was very anæmic and had been so for some considerable time. She was delivered of a still-born child which had probably been dead a week. The placenta was macerated and brownish in colour, but no bad odour could be detected. On the following day the patient was not so well and on the next day the temperature rose to $100^{\circ} \mathrm{F}$. I then gave an intra-uterine douche and ordered a vaginal douche each night. Finding no improvement and the temperature gradually creeping up I sought the assistance 